\title{
ESTUDO COMPARATIVO DO EQUILÍBRIO DE CRIANÇAS SURDAS E OUVINTES
}

\section{Comparative study of balance on deaf and hearing children}

\author{
Marcello Gonçalves de Azevedo ${ }^{(1)}$, Alessandra Giannella Samelli (2)
}

\begin{abstract}
RESUMO
Objetivo: comparar o equilíbrio estático, dinâmico e recuperado de crianças surdas e ouvintes. Métodos: foram avaliadas 9 crianças surdas e 18 crianças ouvintes, de 9 a 12 anos, de ambos os sexos. Foram utilizados os seguintes testes: teste "do quatro" e de Romberg (equilíbrio estático), teste "passeio na trave" e de Unterberger (equilíbrio dinâmico), e giro de 180 (equilíbrio recuperado). Resultados: em todos os testes, a maioria dos ouvintes apresentou equilíbrio estável, enquanto a maioria dos surdos apresentou equilíbrio instável recuperado. Conclusão: a análise dos resultados apontou para um desempenho melhor das crianças ouvintes, em relação às surdas, no que se refere ao equilíbrio estático, dinâmico e recuperado.
\end{abstract}

DESCRITORES: Surdez; Vestíbulo; Orelha Interna

\section{INTRODUÇÃO}

A manutenção do equilíbrio depende da integridade anatômica e funcional do aparelho vestibular, bem como da correlação entre os sistemas visual, proprioceptivo, musculoesquelético e centros ner$\operatorname{vosos}^{1-11}$.

O equilíbrio consiste na manutenção do centro de gravidade dentro da área da superfície de apoio e se apresenta de três formas: equilíbrio estático (exemplo: ficar parado em determinada posição); equilíbrio dinâmico, que é conseguido no movimento e que depende do dinamismo dos processos nervosos (exemplo: o andar) ${ }^{12}$; equilíbrio recuperado, que é a qualidade física que explica a recuperação do equilíbrio numa posição qualquer (exemplo: salto do cavalo, saída da barra fixa, cortada no voleibol) ${ }^{13}$.

O aparelho vestibular, situado na orelha interna, é responsável pela deteç̧ão da posição da cabeça

(1) Educador Físico; Professor de Educação Física da Prefeitura da Estância Hidromineral de Poá, SP; Pós-Graduação Lato Sensu em Educação Especial - Deficiência Auditiva do Centro de Pós-Graduação, Pesquisa e Extensão da Universidade Guarulhos.

(2) Fonoaudióloga; Professora Doutora do Departamento de Fisioterapia, Fonoaudiologia e Terapia Ocupacional da Faculdade de Medicina da Universidade de São Paulo, FMUSP, São Paulo, SP; Doutora em Ciências - Fisiopatologia Experimental pela Faculdade de Medicina da Universidade de São Paulo. em todos os momentos. Quando o aparelho vestibular apresenta algum tipo de distúrbio, o equilíbrio da pessoa pode ser afetado ${ }^{1}$, como é o caso de alguns indivíduos com perda auditiva neurossensorial.

Uma vez que o aparelho vestibular e a cóclea são órgãos anatomicamente muito próximos e devem ser susceptíveis aos mesmos agentes nocivos $^{7-10,14}$, é razoável presumir que muitas crianças surdas têm problemas vestibulares concomitantes à perda auditiva. A hipoatividade vestibular é citada como achado frequente em crianças com perda auditiva severa ${ }^{15}$. Embora a incidência de perda auditiva neurossensorial profunda seja estimada em 1 a cada 1000 nascimentos, a incidência de desordens vestibulares não é amplamente conhecida. Alguns estudos demonstraram que desordens vestibulares são encontradas em aproximadamente 20 a $70 \%$ de crianças com perdas auditivas de diferentes causas $10,16,17$.

Esta desordem vestibular pode afetar a aquisição de habilidades motoras ou interferir na integração sensorial. Um possível retardo no desenvolvimento motor de crianças com surdez neurossensorial pode ser causado pelo déficit na quantidade e/ou qualidade das informações provenientes do apareIho vestibular, incluindo a sensação de equilíbrio e tônus labiríntico, o que dificultaria o estabelecimento das relações com ambiente ${ }^{18,19}$.

A dinâmica corporal do surdo se adapta às informações emitidas pelos órgãos dos sentidos e, se 
bem exploradas, permitem ajustar o equilíbrio aos padrões de normalidade ${ }^{20}$. Por meio de programas de treinamento baseado em exercícios que envolvam o equilíbrio corporal (Exemplo: jogos com bola, trampolim acrobático, dança, entre outros), os surdos podem desenvolver estratégias posturais para superar ou compensar as eventuais dificuldades de equilíbrio ${ }^{21}$.

Estas estratégias posturais são decorrentes da neuroplasticidade, a qual determina que as funções do sistema vestibular afetado possam ser compensadas por outros sentidos, atingindo-se um desenvolvimento semelhante aos dos sujeitos sem alterações no equilíbrio ${ }^{4,7,14}$. É a teoria da compensação ${ }^{17,22}$.

Considerando-se o conjunto de fatores que afetam o equilíbrio do surdo, deve-se destinar atenção especial ao seu desenvolvimento, ainda na pré-escola, buscando uma melhoria constante e levando em conta que, na ausência de comprometimentos de outra natureza, nada impede que seu desenvolvimento motor seja normal ${ }^{20}$.

Em um estudo sobre o assunto em questão, foi observado um desempenho abaixo do normal em relação ao equilíbrio estático de 49 crianças surdas. Após 10 dias de treinamento de atividades para melhorar o equilíbrio estático, não houve uma melhora significativa da performance dos sujeitos comparados com um grupo controle, porém o tempo em que eles conseguiram permanecer num pé só aumentou significantemente. $\mathrm{O}$ autor do trabalho sugeriu que investigações adicionais devem ser feitas de forma a esclarecer o papel de programas de exercícios para a melhora do equilíbrio estático ${ }^{19}$.

Foi realizado um estudo com 40 crianças (idade média de 10 anos, aproximadamente) e foram observadas diferenças significativas no equilíbrio dinâmico de crianças com surdez neurossensorial comparadas com crianças ouvintes, sendo que estas últimas apresentaram um equilíbrio melhor. Este resultado reflete, provavelmente, que estas crianças surdas não aprenderam ainda a antecipar o desequilíbrio, que pode ocorrer durante o teste de equilíbrio dinâmico. Os autores concluíram, ainda, que não existiram diferenças entre sexos, no que se refere ao equilíbrio ${ }^{23}$.

Outro estudo avaliou 30 crianças de ambos os sexos, na faixa etária de 10 a 14 anos, sendo um grupo formado por crianças ouvintes e o outro por crianças com perda auditiva neurossensorial. Foi constatado que as crianças com perda auditiva neurossensorial apresentaram déficits na capacidade motora de equilíbrio estático, em comparação com as crianças ouvintes ${ }^{18}$.

Com base no que foi comentado sobre a possibilidade de alterações do equilíbrio de crianças com perda auditiva neurossensorial e na importância da função vestibular para o equilíbrio, que pode estar afetada nestes indivíduos, em virtude da etiologia da perda auditiva, torna-se fundamental o estudo do assunto em questão, uma vez que o equilíbrio influencia diretamente o desenvolvimento motor e, consequentemente, a adaptação destes indivíduos em situações de vida diária, as quais requerem habilidades motoras específicas.

Sendo assim, o objetivo do presente estudo foi comparar o equilíbrio estático, dinâmico e recuperado de crianças ouvintes e crianças surdas.

\section{MÉTODOS}

A presente pesquisa é prospectiva e de corte transversal. Participaram deste estudo oito crianças com perda auditiva neurossensorial profunda congênita (etiologia desconhecida) e uma com perda auditiva neurossensorial profunda adquirida (por meningite bacteriana contraída aos dois anos).

Este grupo de surdos foi formado por crianças de ambos os sexos, sendo sete do sexo masculino e dois do feminino, com idades entre nove e 12 anos (média de 10,33 anos).

O outro grupo foi formado por 18 crianças ouvintes, de ambos os sexos, sendo nove do masculino e nove do feminino, com idades entre nove e 12 anos (média de 9,88 anos).

Os critérios de inclusão para o grupo dos surdos foram: presença de perda auditiva neurossensorial profunda e faixa-etária entre nove e 12 anos. Todos estes dados foram obtidos nos prontuários das crianças, na própria escola, que continham avaliação audiológica completa atualizada (audiometria total por via aérea e óssea, logoaudiometria e imitanciometria), bem como avaliações complementares (otorrinolaringológica, psicológica, neurológica, entre outras, em alguns casos). Todas as avaliações audiológicas indicavam ausência de comprometimento condutivo associado ao neurossensorial (meatoscopia sem impedimentos e timpanograma do tipo A).

Como critérios de exclusão para este grupo foram considerados: presença de qualquer outra deficiência associada; presença de perda auditiva neurossensorial de leve à severa e faixa-etária acima ou abaixo da estipulada. Novamente, os dados foram obtidos por meio dos prontuários. Além disso, como a escola não atende surdos com outras deficiências associadas (deficiência visual, deficiência mental, etc), este critério de exclusão estava garantido desde o início da seleção dos sujeitos.

Já para o grupo dos ouvintes, o principal critério de inclusão foi a faixa-etária entre nove e 12 anos. Os critérios de exclusão foram: presença de 
qualquer deficiência (neurológica, visual, mental, etc) e faixa-etária acima ou abaixo da estipulada. Estes dados foram obtidos por meio dos prontuários da escola. Todas as crianças deste grupo possuíam limiares auditivos por via aérea melhor do que $20 \mathrm{dBNA}$ nas frequências de $0,25 \mathrm{a} 8 \mathrm{kHz}$, bem como timpanometria tipo $\mathrm{A}$ e presença de reflexos acústicos.

Os testes foram realizados em dois dias nas escolas em que as crianças estudam (duas escolas municipais da cidade de São Paulo).

Para avaliar o equilíbrio estático, dinâmico e recuperado dos participantes da pesquisa, foram utilizadas as seguintes provas:

- Teste Passeio na trave: o avaliado caminha sobre uma trave de equilíbrio, de cinco metros de comprimento por seis centímetros de largura, a cinco centímetros do solo, realizando este percurso caminhando de frente, de costas, lateralmente para a direita e para a esquerda. Este é um teste para verificar o equilíbrio dinâmico ${ }^{24}$.

- Teste do Quatro: o indivíduo fica em pé, apoiado somente em um dos membros, mantendo o outro membro (perna) abduzido e o joelho semiflexionado, com a planta do pé apoiada na altura do joelho, durante dez segundos. Em seguida, o mesmo procedimento é repetido, com a inversão do membro de apoio. Este é um teste para avaliar o equilíbrio estático ${ }^{25}$.

- Teste para avaliar o equilíbrio recuperado: com os pés unidos e braços estendidos ao longo do tronco, saltar fazendo um giro de $180^{\circ}$; durante a fase aérea, os braços ficam estendidos acima da cabeça e voltam à posição inicial no momento da chegada ao solo ${ }^{25}$.

Os critérios de análise para os três testes foram:

- Equilíbrio Estável: quando o indivíduo conseguiu realizar a prova com sucesso, mantendo o equilíbrio durante todo o percurso (passeio na trave), durante todo o tempo (teste do quatro) ou na chegada ao solo (giro de 180);

- Equilíbrio Instável Recuperado: quando o indivíduo se desequilibrou por um instante e recuperou o equilíbrio, sem colocar o(s) pé(s) no solo;

- Equilíbrio Instável com Queda: quando o indivíduo se desequilibrou e colocou o(s) pé(s) no solo e depois voltou ao equilíbrio, continuando o teste;

- Não Realizou: quando o indivíduo não conseguiu manter o equilíbrio, tendo que colocar, a todo o momento, o(s) pé(s) no solo, não executando o teste durante o percurso ou tempo necessários para realizar o mesmo.
O conceito "Instabilidade" foi empregado quando houve: cambaleio, movimento dos pés (sapatear) ou movimentos de oscilação de tronco excessivos ${ }^{26}$.

Para facilitar a análise quantitativa dos dados, o desempenho dos participantes foi pontuado, de acordo com a resposta apresentada, ou seja:

- Equilíbrio Estável - a pontuação foi 3;

- Equilíbrio Instável Recuperado - a pontuação foi 2;

- Equilíbrio Instável com Queda - a pontuação foi 1 ;

- Não Realizou - a pontuação foi 0.

Desta forma, quanto maior a pontuação apresentada na prova, melhor o desempenho do participante. Esta metodologia segue a linha de outros protocolos de avaliação de equilíbrio como, por exemplo, o teste POMA (Performance-Oriented Mobility Assessment) ${ }^{26}$.

Ainda avaliando o equilíbrio estático, foi utilizado também o teste de Romberg: o indivíduo fica em pé, mantendo os pés unidos e os olhos fechados. A observação é se ele mantém o equilíbrio estático, se cai para os lados (lateropulsão), para frente (anteropulsão) ou para trás (retropulsão). No caso de um problema vestibular periférico, a queda apresenta latência e é lateral, enquanto nos casos centrais, o mais comum é que a queda seja para trás, às vezes para frente, e sem latência. Em alguns casos, de pessoas ansiosas ou emocionalmente comprometidas, pode ocorrer apenas um giro do tronco, sem quedas ${ }^{1}$.

Outro teste utilizado na avaliação do equilíbrio dinâmico foi o de Unterberger: o indivíduo marcha no mesmo lugar, com os olhos fechados; observase se ele permanece no mesmo lugar, o que ocorre em pessoas sem alterações, ou se ele gira em torno de seu eixo, sugerindo afecção vestibular ${ }^{1}$.

Todas as crianças foram autorizadas pelos pais ou responsáveis a participar da pesquisa, por meio da assinatura do Termo de consentimento livre e esclarecido.

O primeiro dia de testes foi na escola do grupo de ouvintes. Primeiramente, foi explicado e demonstrado para todas as crianças como seriam realizados os testes. Após a explicação, as crianças foram chamadas uma a uma para realizarem os testes em sequência estabelecida pelo pesquisador.

No segundo dia, foram realizados os testes na escola do grupo de surdos (escola regular, classe especial). Os testes foram explicados oralmente pelo próprio pesquisador e em Libras (Língua Brasileira de Sinais) por uma intérprete. Os testes foram demonstrados para as crianças, que os realizaram 
uma por vez, de forma sequencial, como realizado no grupo dos ouvintes.

Todos os dados foram anotados em folha de registro e, posteriormente, foram tabulados $\mathrm{e}$ analisados.

O protocolo da presente pesquisa foi aprovado pelo Comitê de Ética em Pesquisa da Universidade Guarulhos (SISNEP/14).

A análise estatística foi feita pelo teste ANOVA. O nível de significância assumido foi 0,05.

\section{RESULTADOS}

Não houve diferença estatisticamente significante entre a faixa-etária dos dois grupos $(p=0,31)$.

\section{Equilíbrio Estático}

Como se pôde observar na Tabela 1, tanto na etapa direita quanto esquerda, houve diferença estatisticamente significante entre os dois grupos, sendo que o desempenho do grupo dos ouvintes foi superior ao grupo dos surdos, já que obtiveram melhores escores.

Com relação ao teste de Romberg, de acordo com a Figura 1, nota-se que nenhum sujeito do grupo dos ouvintes apresentou alteração nesta prova, enquanto somente $33,3 \%$ dos surdos apresentaram resultados normais.

\section{Equilíbrio Dinâmico}

De acordo com a Tabela 2, verificou-se que, o grupo dos ouvintes saiu-se melhor em todas as etapas desta prova, uma vez que o escore médio dos participantes ouvintes foi melhor que o dos surdos. Nas etapas andar para frente e lateralmente para direita, a diferença entre os grupos foi estatisticamente significante.

O teste de Unterberger também mostrou melhor desempenho do grupo dos ouvintes, uma vez que não houve nenhum sujeito deste grupo que falhou nesta prova; por outro lado, apenas $33,3 \%$ dos surdos apresentaram resultados normais nesta prova (Figura 2).

\section{Equilíbrio recuperado}

Da mesma forma que nos testes anteriores, a Tabela 3 evidencia uma melhor performance dos ouvintes, em relação aos surdos, porém sem diferença estatisticamente significante.

Tabela 1 - Desempenho dos surdos e dos ouvintes no Teste do Quatro

\begin{tabular}{cccccc}
\hline & \multicolumn{3}{c}{ 4D } & & \multicolumn{3}{c}{ 4E } \\
\hline Média & Surdos & & Ouvintes & Surdos & Ouvintes \\
DP & 1,66 & & 2,38 & 1,44 & 2,38 \\
p & 1 & & 0,6 & 0,88 & 0,69 \\
\hline
\end{tabular}

Legenda: 4D - Teste do quatro para o lado direito; 4E - Teste do quatro para o lado esquerdo (teste ANOVA)

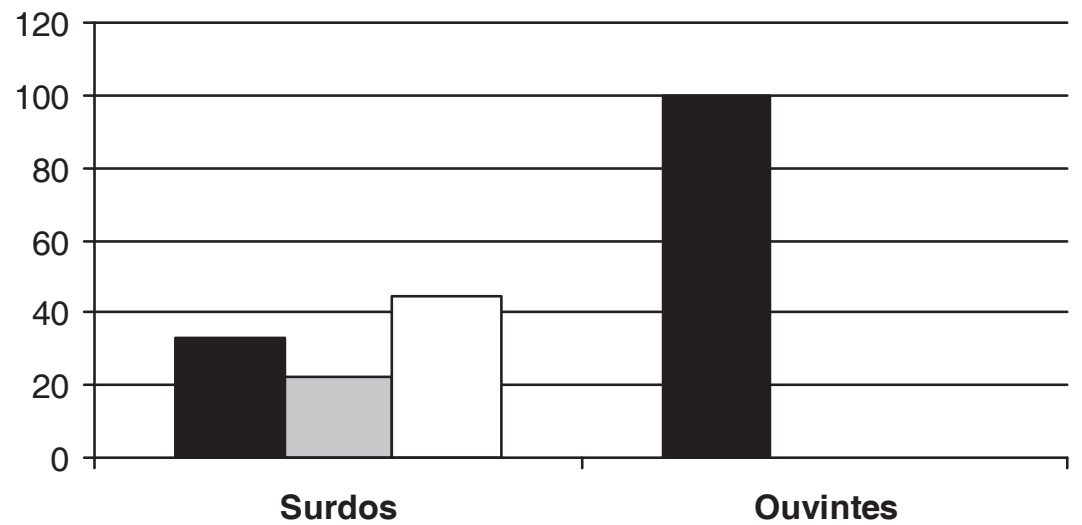

Normal $\square$ Giro D $\square$ Giro E

Figura 1 - Desempenho dos surdos e dos ouvintes no Teste de Romberg (em \%) 
Tabela 2 - Desempenho dos surdos e dos ouvintes no Teste Passeio na trave

\begin{tabular}{cccccccccc}
\hline & \multicolumn{2}{c}{ Trave F } & \multicolumn{2}{c}{ Trave T } & \multicolumn{2}{c}{ Trave LD } & \multicolumn{2}{c}{ Trave LE } \\
\hline & Surdos & Ouvintes & Surdos & Ouvintes & Surdos & Ouvintes & Surdos & Ouvintes \\
Média & 2,22 & 2,77 & 1 & 1,39 & 0,78 & 1,15 & 1 & 1,44 \\
DP & 0,67 & 0,55 & 0,5 & 0,7 & 0,67 & 0,7 & 0,5 & 0,61 \\
P & \multicolumn{2}{c}{$0,029^{*}$} & \multicolumn{2}{c}{0,15} & & \multicolumn{2}{c}{$0,017^{*}$} & \multicolumn{2}{c}{0,072} \\
\hline
\end{tabular}

Legenda: F - frente; T - trás; LD - lateral direito; LE - lateral esquerdo (teste ANOVA)

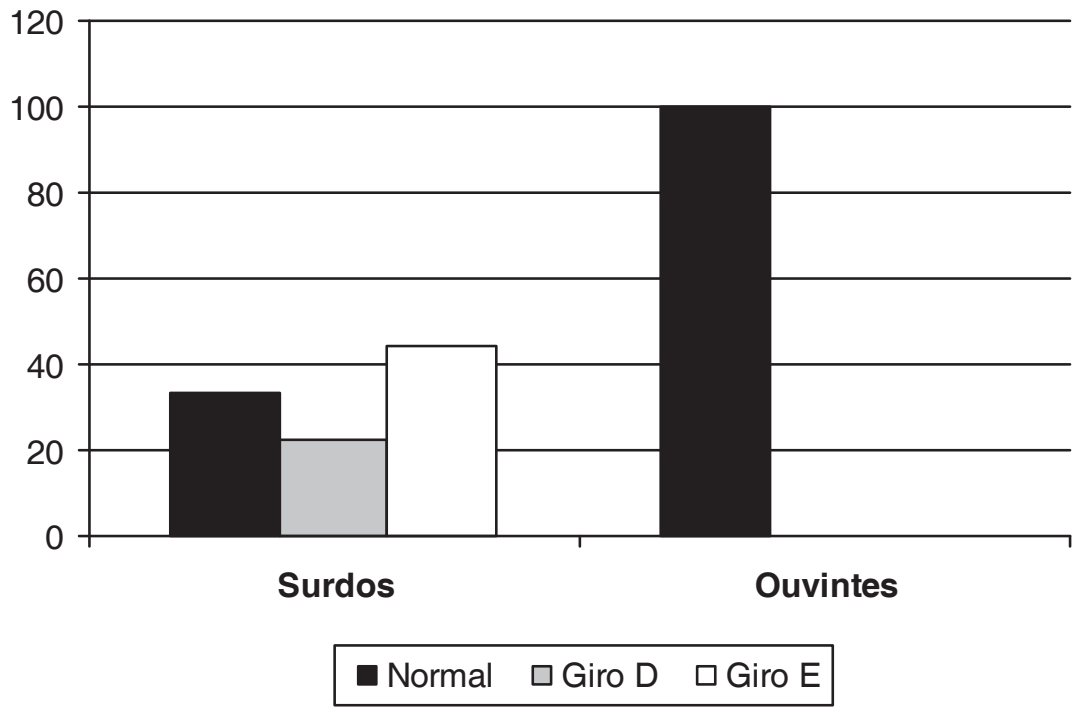

Figura 2 - Desempenho dos surdos e dos ouvintes no Teste de Unterberger (em \%)

Tabela 3 - Desempenho dos surdos e dos ouvintes no Teste giro de 180을

\begin{tabular}{ccc}
\hline & \multicolumn{3}{c}{$\mathbf{1 8 0}^{\circ}$} \\
\hline Média & Surdos & Ouvintes \\
DP & 2,44 & 2,77 \\
p & 0,52 & 0,42 \\
\hline
\end{tabular}

Legenda: $180^{\circ}-$ Teste giro de $180^{\circ}$ (teste ANOVA)

\section{DISCUSSÃO}

Os resultados obtidos no presente estudo, embora sejam de uma amostra pequena, revelaram diferenças significantes entre os grupos dos surdos e dos ouvintes, no que se refere ao equilíbrio estático, sendo que o grupo dos ouvintes apresentou um desempenho melhor que o grupo dos surdos, como ocorreu nos trabalhos feitos por vários autores $8,18,19,23$ nos quais as crianças portadoras de perda auditiva neurossensorial apresentaram um déficit na capacidade de equilíbrio estático, em comparação com as crianças ouvintes. Em relação ao desempenho inferior dos surdos no teste de Romberg, cabe ressaltar que a retirada da pista visual (olhos fechados) compromete ainda mais a manutenção do equilíbrio destes indivíduos ${ }^{5,7,9}$, uma vez que, provavelmente, já possuem uma defasagem vestibular.

Com relação ao equilíbrio dinâmico, os resultados também demonstraram um desempenho superior do grupo dos ouvintes, em relação ao grupo dos surdos, o que está de acordo com os achados de outros autores ${ }^{8,9,23}$, que encontraram diferenças entre crianças surdas e ouvintes, no que se refere ao equilíbrio dinâmico.

O teste de Unterberger também demonstrou uma defasagem do equilíbrio dinâmico dos surdos em comparação com os ouvintes. Novamente, vale comentar que houve a retirada da pista visual durante esta prova, prejudicando ainda mais o desempenho dos surdos ${ }^{7}$.

A prova que avalia o equilíbrio recuperado (giro de $\left.180^{\circ}\right)$, da mesma forma que as provas que avaliam o equilíbrio estático e dinâmico, apresentou melhores resultados no grupo dos ouvintes do que no grupo dos surdos, embora a diferença não tenha sido estatisticamente significante. Outros autores ${ }^{16}$ também observaram uma pequena diferença entre 
os grupos, a favor dos ouvintes; os autores comentaram que, provavelmente, as crianças surdas aprenderam a compensar o déficit vestibular com os outros órgãos responsáveis pelo equilíbrio e este fato explicaria esta pequena diferença encontrada entre os dois grupos.

Cabe ressaltar, com relação ao uso de apenas um sujeito com perda auditiva adquirida, que se tentou comparar seu desempenho com o dos outros (com perda auditiva congênita), visando verificar se existiu um possível efeito da época de aquisição / etiologia da perda auditiva sobre o equilíbrio, como já descrito anteriormente na literatura ${ }^{21}$. No entanto, nenhum padrão de respostas pôde ser estabelecido, uma vez que seu desempenho foi semelhante ao dos outros indivíduos. Desta forma, outros estudos sobre o assunto poderiam realizar esta comparação com um maior número de sujeitos, buscando confirmar ou refutar esta hipótese.

Sendo assim, com base nos achados do presente trabalho, pode-se afirmar que o grupo dos ouvintes apresentou equilíbrio estático, dinâmico e recuperado melhor que o grupo dos surdos.

Este fato está relacionado, possivelmente, com a perda auditiva neurossensorial, uma vez que crianças, com este tipo de surdez, podem apresentar, concomitantemente, alterações de equilíbrio causadas pelo déficit na quantidade e/ou qualidade das informações provenientes do aparelho vestibuIar ${ }^{17,18}$.

Em uma investigação sobre o tema, foi referido que atividades motoras, as quais dependem do equilíbrio, em fases iniciais de trabalho, apresentam diferenças de desempenho dos surdos em relação aos ouvintes. Contudo, sendo o equilíbrio uma habilidade passível de ser desenvolvida e aperfeiçoada por meio de experiências corporais, a defasagem, anteriormente observada entre os grupos de surdos e ouvintes, tende a diminuir. Foi comentado, ainda, que um trabalho de desenvolvimento motor com surdos não requer grandes adaptações e que os objetivos maiores, neste caso, são: levá-los a desenvolver a autoconfiança, a melhora da coordenação geral e do equilíbrio (estático, dinâmico e recuperado), bem como da velocidade de reação e da agilidade ${ }^{27}$.

Estudos futuros sobre o assunto deveriam aprofundar a avaliação feita no presente trabalho, acrescentando avaliações posturais e uma análise da marcha, nos dois grupos. Seria interessante, também, ampliar a faixa-etária avaliada, utilizando pessoas de várias idades, divididas em subgrupos por faixa-etária, para investigar um possível efeito da idade sobre o equilíbrio ${ }^{21}$.

Além disso, outros estudos deveriam investigar o efeito de um programa de treinamento sobre o equilíbrio dos surdos, visando diminuir possíveis diferenças encontradas entre os grupos de surdos e ouvintes.

Sabe-se que os surdos podem desenvolver estratégias posturais para superar ou compensar as dificuldades de equilíbrio ${ }^{21}$. Sendo assim, seria importante que avaliações e treinamentos específicos fossem incorporados no dia-a-dia de escolas e instituições que atendem esta população, procurando melhorar o desempenho do equilíbrio de crianças com perdas auditivas neurossensoriais, buscando adequar ou aprimorar seu desenvolvimento motor e sua qualidade de vida ${ }^{28}$.

\section{CONCLUSÃO}

Houve diferença entre o desempenho das crianças surdas e ouvintes, quanto ao equilíbrio estático, dinâmico e recuperado, sendo que os ouvintes apresentaram melhores resultados do que os surdos.

\begin{abstract}
Purpose: to compare the static, dynamic and recovered balance of deaf and hearing children. Methods: nine deaf children and eighteen hearing children were evaluated (age nine to twelve, both sexes). To evaluate the static, dynamic and recovered balance, we used the "four" test, Romberg test, the "spend on the bridge" test, Unterberger test and 180 test, respectively. Results: in all tests, most of hearing children showed steady balance and most of deaf children showed unstable recovered balance. Conclusion: the analysis of results led to a conclusion that hearing children have best performance than deaf children, regarding static, dynamic and recovered balance.
\end{abstract}

KEYWORDS: Deafness; Vestibule; Ear, Inner 


\section{REFERÊNCIAS}

1. Mor R, Taguchi KC, Figueiredo JFFR. Vestibulometria e fonoaudiologia: como realizar e interpretar. São Paulo: Lovise; 2001.

2. Baraúna MA, Duarte F, Sanchez HM, Canto RST, Malusá S, Campelo-Silva CD, Ventura-Silva RA. Avaliação do equilíbrio estático em indivíduos amputados de membros inferiores através da biofotogrametria computadorizada. Rev Bras Fisioterap. 2006; 10(1):83-90.

3. Almeida LD, Mitre El, Lemos L, Simões ECC. Vestibulometria em indivíduos com zumbido e exames audiológicos normais. Rev CEFAC. 2005; 7(3):382-7.

4. Medeiros IR, Bittar RS, Pedalini ME, Lorenzi MC, Formigoni LG, Bento RF. Vestibular rehabilitation therapy in children. Otol Neurotol. 2005; 26(4):699-703.

5. Steindl R, Kunz K, Schrott-Fischer A, Scholtz AW. Effect of age and sex on maturation of sensory systems and balance control. Dev Med Child Neurol. 2006; 48(6):477-82.

6. Ferber-Viart C, Lonescu E, Morlet T, Froehlich $P$, Dubreuil C. Balance in healthy individuals assessed with equitest: maturation and normative data for children and young adults. Int $\mathrm{J}$ Pediatr Otorhinolaryngol. 2007; 71(7):1041-6.

7. Suarez H, Angeli S, Suarez A, Rosales B, Carrera X, Alonso R. Balance sensory organization in children with profound hearing loss and cochlear implants. Int J Pediatr Otorhinolaryngol. 2007; 71(4):629-37.

8. Gheysen F, Loots G, Van Waelvelde H. Motor development of deaf children with and without cochlear implants. J Deaf Stud Deaf Educ. 2008; 13(2):215-24.

9. Cushing SL, Chia R, James AL, Papsin BC, Gordon KA. A test of static and dynamic balance function in children with cochlear implants: the vestibular olympics. Arch Otolaryngol Head Neck Surg. 2008; 134(1):34-8.

10. Cushing SL, Papsin BC, Rutka JA, James AL, Gordon KA. Evidence of vestibular and balance dysfunction in children with profound sensorineural hearing loss using cochlear implants. Laryngoscope. 2008; 118(10):1814-23.

DOI: 101590 / S1516 - 18462009005000014

RECEBIDO EM: 09/09/2007

ACEITO EM: 19/05/2008

Endereço para correspondência:

Alessandra Gianella Samelli

Centro de Docência e Pesquisa em Fisioterapia,

Fonoaudiologia e Terapia Ocupacional - Cidade

Universitária

Rua Cipotânea, 51 - SP - São Paulo

CEP: 05360-000

E-mail: alesamelli@usp.br
11. Wiener-Vacher SR. Vestibular disorders in children. Int J Audiol. 2008; 47(9):578-83.

12. Correa MF. As capacidades físicas do jogador de futebol. [serial on the internet] 2002. Disponível em: http://www.marciofariacorrea.com/preparação02. htm Acesso em 02 dez 2004.

13. Tubino JGM. Metodologia científica do treinamento desportivo. São Paulo: IBRASA; 1980.

14. Kaga K, Shinjo Y, Jin Y, Takegoshi H. Vestibular failure in children with congenital deafness. Int $\mathrm{J}$ Audiol. 2008; 47(9):590-9.

15. Lisboa TR, Jurkiewicz AL, Zeigelboim BS, Martins-Bassetto J, Klagenberg KF. Achados vestibulares em crianças deficientes auditivas. Arq Otorrinolaringol. 2005; 9(4):271-9.

16. Potter CN, Silverman LN. Characteristics of vestibular function and static balance skills in deaf children. Phys Ther. 1984; 64(7):1071-5.

17. Angeli S. Value of vestibular testing in young children with sensorineural hearing loss. Arch Otolaryngol Head Neck Surg. 2003; 129(4):478-82. 18. Araújo SM, Meira Júnior CM, Cantarelli EM. Equilíbrio estático em crianças portadoras de deficiência auditiva neurossensorial. Cad UniABC de Educação Física. 2001; 16:56-70.

19. Effgen SK. Effect of an exercise program on the static balance of deaf children. Phys Ther. 1981; 61(6):873-7.

20. Almeida AC. Surdez, paixão e dança. São Paulo: Olho d'água; 2000.

21. Campos $C$. Efeitos de um programa de treinamento com trampolim acrobático sobre o equilíbrio de crianças surdas. Rev Sobama. 2003; 8(1):21-6.

22. Mariotto LDF, Alvarenga KF, Costa Filho AO. Avaliaçãovestibularnaperdaauditiva sensorioneural unilateral: estudo vecto-eletronistagmográfico. Dist Comun. 2006; 18(1):27-38.

23. Gayle GW, Pohlman RL. Comparative study of the dynamic, static, and rotary balance of deaf and hearing children. Percept Mot Skills. 1990; 70(3Pt1):883-8.

24. Carnaval PE. Medidas e avaliação em ciências do esporte. 2. ed. Rio de Janeiro: Sprint; 1997.

25. Gorla Jl. Educação Física Especial: testes. 1. ed. Rolândia: Physical-Fisio; 1997.

26. Gomes GC. Tradução, adaptação transcultural e exame das propriedades de medida da escala "performance-oriented mobility assessment" (POMA) para uma amostragem de idosos brasileiros institucionalizados [dissertação]. Campinas (SP): Universidade Estadual de Campinas; 2003.

27. Amadeu PA. O surdo e a ginástica acrobática. Rev Arqueiro. 2001; (4);23-5.

28. Nandi R, Luxon LM. Development and assessment of the vestibular system. Int $\mathrm{J}$ Audiol. 2008; 47(9):566-77. 